\title{
Processing Instruction: A Review of Issues
}

\author{
Muhlisin Rasuki* \\ Fakultas Keguruan dan Ilmu Pendidikan, Universitas Muhammadiyah Jember, Jawa Timur, Indonesia
}

Corresponding author: Muhlisin Rasuki, E-mail: muhlisinrasuki@gmail.com

\begin{tabular}{l} 
ARTICLE INFO \\
\hline Article history \\
Received: May 28, 2017 \\
Accepted: July 18, 2017 \\
Published: July 31, 2017 \\
Volume: $5 \quad$ Issue: 3
\end{tabular}

Conflicts of interest: None Funding: None

\begin{abstract}
This paper provides a critical review of Processing Instruction (PI). This type of instructional option was specifically designed to help second/foreign language (L2) learners grasp meaning manifested in the use of particular grammatical forms in a target language effectively through the provision of input. In this way, PI attempts to help learners develop grammatical competence in a target language in ways that foster their comprehension and production skills. The paper starts with outlining main characteristics of PI which distinguish it from other types of L2 grammar instruction. Then, a large body of research attempting to investigate the relative efficacy of PI is scrutinized. The paper concludes with a number of important issues that future studies on PI need to address.
\end{abstract}

Key words: Processing Instruction (PI), Input Processing Theory (IP), Grammar Instruction

\section{INTRODUCTION}

Processing Instruction (PI) refers to a particular type of input-based grammar instruction specifically designed to help learners link and acquire grammatical forms and meaning in a target language (L2) effectively through the provision of input (VanPatten, 1996, 2002, 2004). Unlike traditional instruction which emphasizes teaching grammatical rules explicitly to learners, PI involves giving learners explicit information of target grammatical forms briefly and then guiding them to mentally process meaning manifested in the use of certain grammatical forms (Wong, 2004).

The first study on the relative efficacy of PI was conducted by VanPatten and Cadierno (1993). In the study, the researchers compared the relative effectiveness of traditional instruction and PI in assisting learners to acquire objects pronouns and word order in Spanish as an L2. The traditional instruction comprised explicit information about the target grammatical forms as well as opportunities to practice producing the target grammatical forms (i.e., objects pronouns and word order in Spanish). Meanwhile, PI only consisted of giving learners explicit information about the target forms as well as opportunities to "process" meaning of the forms through the so-called "structured-input activities". The results of the study indicated that learners learning under the PI condition made "significant gains in both comprehension and production" (p. 225), whereas those learning under the traditional instruction made significant gains only in production. Based on these results, VanPatten and Cadierno (1993) concluded that PI was more effective than traditional instruction in facilitating L2 acquisition.

A couple of years later, Cadierno (1995) conducted another replication study on the effectiveness of PI. In the study,
Cadierno again compared the effects of traditional instruction and PI on the acquisition of past tense form in Spanish. Sixty one L2 Spanish learners were recruited as research subjects. The subjects were assigned to one of three conditions: traditional instruction, PI, and control. The results again showed that PI was more effective than traditional instruction in facilitating acquisition of L2 grammatical forms.

To date, there have been a plethora of studies conducted to examine the relative efficacy of PI in facilitating acquisition of grammatical forms in an L2 (Shintani, 2015a). These studies were conducted with different aims, including, for instance, to examine the relative effectiveness of PI in assisting the acquisition of grammatical forms in different languages, such as Japanese (e.g., Benati, 2015), English (e.g., Benati \& Angelovska, 2015), French (e.g., VanPatten \& Wong, 2004) and even Latin (e.g., Cox \& Sanz, 2015), or to compare the effectiveness between PI and other instructional options, such as Meaning-Based Output Instruction (e.g., Farley, 2001a; VanPatten, Farmer \& Clardy, 2009), dictogloss tasks (Qin, 2008; VanPatten, Inclezan, Salazar, \& Farley, 2009), text reconstruction tasks (Wong, 2015), etc. In general, the results of the series of these studies indicated that PI was more effective than all of the instructional options with which it was compared. Nonetheless, despite the results of these studies, PI still suffers from criticisms (e.g., DeKeyser et al., 2002). One of them, for instance, is especially related to the theoretical claim made by PI proponents in that input alone is sufficient to help L2 learners develop their underlying L2 knowledge, i.e., the type of knowledge which can be tapped during online comprehension and production (VanPatten, 2015a, 2015b). In fact, VanPatten $(2002,2004)$ argued that requiring learners to 
attend to both input and output simultaneously during the course of learning can impede the development of their underlying L2 knowledge.

Another criticism of PI is related to the design and measurement applied in the studies. Shintani (2015a), for instance, stated that the tests used to measure the learning outcomes in PI studies were mostly similar to the instructional materials used in teaching learners in PI groups but not to those in the comparative groups. As such, the significant gains made by learners in the PI groups might have been due to their being familiar with the nature of the test materials given. Therefore, although there have been a quite large number of studies which indicated that PI was effective, further studies are still needed to further examine the true efficacy of PI. However, as it will become clear from the discussion in the next sections, further studies need to consistently operationalize any instructional conditions in which PI is investigated and-insofar the PI condition is concerned-researchers will need to apply theoretical principles underlying PI into their specific PI condition. The latter is of paramount importance to consider since, as VanPatten (2002) noted, there have been a number of replication studies aiming to investigate the effectiveness of PI which have failed to apply the theoretical principles governing the instructional option (PI). As such, the outcomes of those studies cannot be taken as evidence either to reject or support the effectiveness of PI at all.

Motivated by the continuing debate and interest in PI, this review therefore aims to

1. identify the main characteristics of PI which distinguish it from other types of input-based L2 grammar instruction,

2. examine the relative efficacy of PI as compared with other types of instructional conditions,

3. put forward a number of limitations in a range of studies on PI to date, and

4. extract key issues that future studies on PI will need to address.

\section{MAIN CHARACTERISTICS OF PI}

There are two main characteristics which distinguish PI from other types of input-based L2 grammar instruction (e.g. input enhancement, input-based task instruction, etc.). First, it is theoretically governed by Input Processing theory. Second, it is applied through a certain model of "structured-input activities". These two characteristics are discussed below.

\section{Input Processing Theory}

Input processing theory (IP) is concerned with default mental processing strategies that L2 learners employ when receiving input. According to the theory, these default mental strategies are ineffective in that they usually lead learners to engage in inaccurate/inappropriate processing (VanPatten, 2015b).

There are three default mental processing strategies that IP suggests. Each of the three mental processing strategies is explained in terms of "processing principles" which include
(1) the lexical preference principle, (2) the first-noun principle, and (3) the sentence location principle.

\section{The lexical preference principle}

This first principle states that when processing meaning of a sentence or utterance, L2 learners focus on processing lexical rather than grammatical items (VanPatten, 2002, 2015a, 2015b). Hence, when L2 learners of English, for instance, read or listen to the sentence "He printed the paper for me yesterday", they will hardly process the meaning of morphological form/inflection -ed attached to the verb "print" to mean that the action happened in the past. Rather, their default mental processing strategies will, by default, draw their attention to focus on the lexical item "yesterday" which overtly indicates the meaning of pastness.

\section{The first-noun principle}

According to this principle, L2 learners tend to assign the first noun phrase as the agent of a sentence or utterance (VanPatten, 2002, 2015a, 2015b). Thus, when L2 learners of English read or listen to a passive sentence like "I was helped by her" in which the two pronouns (I and her) are capable of performing the action of helping, learners will misinterpret the sentence as "I helped her" (i.e., assigning the first pronoun (I) as the agent). However, when a passive sentence denotes an action which can only be attributed to a pronoun or noun phrase only, as in "The money was stolen by a thief', learners will directly process the meaning of the sentence correctly as it is supposed to mean. In such a case, learners process the meaning of the passiveness based on "event probability" rather than "the first-noun principle" (VanPatten, 2002, 2015b).

\section{The sentence location principle}

The sentence location principle states that when processing a sentence or utterance, L2 learners tend to focus on a unit (a word or phrase) that is located in the initial position in a sentence. Subsequently they will process the unit in the final position, while the unit in the medial position is processed last (VanPatten, 2002, 2015a, 2015b). As such, this principle implies that L2 learners process a unit in the initial position faster than that in the final and, especially, in the medial position. This principle is derived from the evidence that those learning a simple yes/no question formation in Spanish know without being told that the question is formed by means of subject and verb inversion (i.e., a verb is put before a subject). In such a case, learners quickly see that verb goes before subject in a simple yes/no question formation in Spanish (VanPatten, 2002, p. 761).

VanPatten (2015b) states that these three default mental strategies "do not act in isolation" (p. 122). However, in conducting a study on PI, researchers will need to address only one default mental strategy that is likely to play a primary role in learners' default mental processing, be it the lexical preference, first-noun or sentence location principle. 


\section{Structured-Input Activities}

Structured-input activities in PI consist of two main activities, namely, referential and affective.

\section{Referential activity}

Referential activity consists of a set of activities that aim to help L2 learners process input effectively and accurately (VanPatten, 2002). In this activity, learners are usually provided with a set of sentences containing a target grammatical form and other similar forms as distracters. They are then expected to respond to the sentences and will be told if their responses are right or wrong (see below). However, there will be no explanation given to them as to why their answer is right or wrong. In this way, learners are encouraged to mentally assign the surface components of the target language they encounter with their meaning and function (VanPatten, 2015a).

For instance, in a task aiming to teach the causative construction in English, learners might be given the following activity.

Activity I. Listen to each sentence and answer each question given.

1. The teacher had John clean the board.

2. John brought the girl some flowers.

3. The men made Richard buy some bread.

4. Jean asked Jack for a lift.

5. The girl made the boy pay the bill.

6. He bought me a book about happiness.

(cf., VanPatten, 2002; Wong, 2004)

In accordance with each sentence above, learners might be given a series of questions, such as, 'Who cleaned the board?', 'Who brought the flowers?', etc. and asked to answer each question given. Alternatively, learners might also be given a pair of pictures related to each sentence and then asked to show which picture best corresponds to the meaning of each sentence. The way in which each sentence and question is given takes place in sequence. That is, learners are required to give their response directly after each of the prompt sentences is given. Similarly, the teacher then gives his/her feedback right after learners give their response.

When giving feedback the teacher should simply say if learners' answer is right or wrong and let them think to figure out the correct causative construction by themselves. VanPatten (2002) claimed that it is important that sentences include distracter items related to the target grammatical form that learners are to learn so "learners are pushed to listen to every sentence and not apply a strategy that judges all sentences to be causative simply because that is the grammatical point that they are learning" (p. 766). Based on the six sample sentences above, the target grammatical form (causative construction) is included in sentences number 1,3 and 5 , while the distracter is embedded in sentences number 2, 4 and 6 .

\section{Affective activity}

Affective activity follows the referential activity. In affective activity, learners are usually given a series of sentences and asked to express their opinions, beliefs or some other types of affective response (VanPatten, 2002). However, while doing this activity, learners must not produce sentences containing the target structure (Benati \& Angelovska, 2015, p. 256). Instead, they are only expected to respond to the sentence prompts by saying "agree" or "disagree", "true" or "not true", etc. As such, this activity aims only at reinforcing learners' accurate processing strategy that has been established while completing referential activity.

For instance, in line with Activity I above, learners might then continue doing Activity II below to reinforce their processing of the causative construction.

Activity II. Listen to the sentences about what teachers ask students to do. Say 'Yes' if you think the actions asked by the teachers are common. Say 'No' if you think what the teachers ask is not common.

1. Teachers have their students kill animals.

2. Teachers get their students do homework.

3. Teachers make their students study hard.

4. Teachers get their students clean the school yard.

5. Teachers make their students listen to their explanation.

6. Teachers have their students play a videogame in the classroom.

As the same as Activity I above, each sentence is given one by one in sequence and learners are expected to respond to the sentence directly by saying 'yes' or 'no'. Different from the sentences in Activity I, however, all sentences in Activity II must contain the target form (cf., VanPatten, 2002; Wong, 2004).

\section{Explicit Information}

In addition to structured-input activities, those intending to conduct a study on PI may also apply explicit information in their treatment. Applying explicit information in PI, however, is optional since, as VanPatten et al. (2013) put it, even without the help of explicit information, learners will still manage to catch up the rate of input processing as those who process input with the help of explicit information.

When researchers choose to apply explicit information in their PI treatment, however, it must contain information about the target form that learners are to learn along with the default mental strategies that they are likely to employ when processing the form (Benati \& Angelovska, 2015). Also, it must be given prior to structured-input activities.

To use the same target form exemplified in Activity I and II above, for instance, researchers might first give a brief explanation about the form (causative construction in English). The explanation is usually given in learners' first language to ensure the clarity. Then, they need to inform learners about their potential problems in processing the form. In the case of causative construction, their processing problems might be related to the first-noun principle. That is, when listening to the sentence "The men made Richard buy some bread", learners are believed to interpret that it is "the men" who bought some bread, not Richard.

After being told that such processing is inaccurate, researchers then advise the learners about a more accurate processing strategy. The advice might include information like: 
in the sentence "The men made Richard buy some bread", the agent of the action "bought" should be assigned to "Richard', not to 'the men'. To make the advice even clearer, researchers may provide further but brief explanation as to why it is Richard instead of the men who bought some bread (Benati \& Angelovska, 2015).

To summarize, when intending to conduct a study on PI, researchers need to:

1. choose a particular grammatical form which learners have not mastered yet.

2. consider learners' potential problem in processing the grammatical form based on the relevant default mental strategies postulated in Input Processing theory (IP).

3. either include or exclude explicit information in the beginning of the treatment.

4. apply structured-input (referential and affective) activities.

\section{PI VS. OTHER INSTRUCTIONAL OPTIONS}

Quite recently Wong (2015) conducted a study to examine the effectiveness of three instructional conditions: (1) input-based instruction which required learners to process a target form, (2) input-based instruction which exposed learners to a target form but did not require processing, and (3) input-plus-output-based instruction which required learners to process and produce a target form. The first condition in Wong's (2015) study was operationalized through PI, the second one was through reading comprehension (COMP), and the third one was through text reconstruction (TR). The target form selected in the study was the causative construction in French, and the instructional material used in all three conditions was a short story containing 316 words. Insofar the PI condition is concerned, the processing problem which it aimed to address was the first-noun principle.

There were 60 college students of English background included in Wong's (2015) study. The students were divided into four groups: PI $(N=19)$, (TR) $(N=14)$, (COMP) $(N=15)$, and control $(\mathrm{C})(N=12)$. The treatment condition received by the PI group included structured-input activities only without the provision of explicit information. Meanwhile, the treatment condition received by the TR group included listening, reading, note-taking and reconstructing the story given. The treatment condition received by the COMP group included listening to a recording containing the story and reading along on paper copy. The $\mathrm{C}$ group did not receive any instruction and was only given a pre-test and posttests. All of these treatment conditions were given in a day only and lasted between 30 to 40 minutes each.

For the assessment Wong (2015) included an interpretation and production test. These tests consisted of two types: A and B. Type A was given in both pre-test and delayed posttest, while type $\mathrm{B}$ was given in the immediate post-test. The interpretation test was given in a form of a listening activity which required the students to listen to a series of sentences and then indicate a particular action corresponding to the meaning of each sentence. The production test was given in a form of writing task which required the students to write a sentence to describe a picture of people doing a certain ac- tion. There were 10 pictures altogether. From these ten pictures, five required the students to use the target grammatical form while the other five did not. To ensure that the students did not have any significant difference in their reading comprehension skills, Wong (2015) gave them a reading comprehension test before the treatments.

The results of Wong's (2015) study showed that the students in PI group outperformed those in the other three groups (TR, COMP, and C) both in the interpretation and production tasks, while the three groups made no gains in either interpretation or production task. Based on these results, Wong (2015) concluded that structured-input activities included in PI are effective in that the activities are not only input-oriented but more importantly "they are designed to help process input better" (p. 200).

However, despite being carefully controlled, there is a big limitation in Wong's (2015) study - and indeed in the majority of studies on PI. This limitation is related to the fact that the study was conducted in a very short time. In order that the results of a study can be deemed much more suggestive, conducting a longitudinal study to examine the true efficacy of PI is necessary (cf., DeKeyser \& Botana, 2015).

While Wong's (2015) study is quite new and as such has not impacted much on the discussion about PI, classic studies on PI conducted by Farley (2001a, 2001b), however, have generated debate and some contention among researchers. In his first published study on PI, Farley (2001a) extended IP (Input Processing theory) toward output-based instruction which he called Meaning-Based Output Instruction (MOI). The main difference between PI and MOI is that the former concerns with structured-input activities whereas the latter concerns with structured-output activities (Farley, 2001a, p. 291). The operationalization of PI and MOI in Farley's (2001a) study was as follows:

1. The PI group received a treatment condition through explicit information and structured-input activities, while the MOI group received explicit information and structured-output activities.

2. The structured-input activities in the PI group followed the standard model as discussed above, while the structured-output activities in the MOI group required that the subjects produce the target form through communicating opinions, beliefs or other types of information related to a topic given.

The grammatical form selected in the study was subjunctive forms in Spanish and the processing problem that both PI and MOI aimed to address was the lexical preference principle.

Farley (2001a) recruited 29 university students of English background in the study. The subjects were divided into two groups: MOI $(N=19)$ and PI $(N=17)$. The treatment of the two conditions was conducted within two days with a posttest given a day after the last treatment and a delayed post-test given after a month. The treatment materials in the study included a series of sentences with the target structure. The same case also applied to the assessment materials. These materials consisted of both interpretation and production sentence-level test. In the interpretation test, the subjects in both groups 
were first given incomplete sentences along with two options for each sentence. They were then required to listen to a series of sentences and then choose one of two options that best completed the sentences. For the production test, the subjects were only required "to change the infinitive verb form in parenthesis (if necessary) to fill in the blank and complete each sentence correctly" (Farley, 2001a, p. 293). The results of this study show that PI group performed better than MOI group in both interpretation and production test. Farley (2001a) concluded that " $[\mathrm{t}]$ he results of the study indicate that PI has an overall greater effect than MOI on how learners interpret and produce the Spanish subjunctive of doubt" (p. 295).

However, in another study where Farley (2001b) again compared the effectiveness of PI and MOI, the results were different from those in his earlier study (Farley, 2001a). In general, the results of his second study show that both PI and MOI group performed equally well in both interpretation and production test after the treatments. These inconsistent findings concerning the effectiveness of PI and MOI have since then motivated a number of replication studies including the one by Benati (2005), Morgan-Short and Bowden (2006), Keating and Farley (2008), Farley (2004), and VanPatten, Farmer and Clardy (2009), amongst others. Instead of finding fixed results, these replication studies further extend inconsistency in findings. For instance, while Benati (2005) as well as VanPatten, Farmer and Clardy (2009) found that PI is more effective than MOI, Morgan-Short and Bowden (2006) as well as Keating and Farley (2008) found that MOI is more effective than PI. Responding such mixed findings, VanPatten et al. (2009) stated that MOI needed to be operationalized more consistently in future studies.

Nonetheless, in the studies where MOI is found more effective than PI (e.g., Morgan-Short and Bowden, 2006), there appeared that the materials used in the structured-output activities were operationalized through the principle of "task-essentialness" (Loschky \& Bley-Vroman, 1993). That is, the instructional materials used in the structured-output activities were designed in a way that learners needed to specifically attend to the target structure in order to be able to complete the tasks successfully (DeKeyser \& Botana, 2015). In other words, when the instructional materials used in the structured-output activities were designed in a mechanical way, learners would fail to process a target grammatical form. By contrast, if the materials were task-essential, learners would be able to process a target grammatical form successfully. The example of a mechanical output-based instructional materials was especially evident in Farley's (2001a) study where the subjects were required only to "create meaning by completing sentences via producing subordinate clauses containing present-tense subjunctive forms" (p. 292 emphasis added), while the example of task-essential output-based materials were evident in Morgan-Short and Bowden's (2006) study. That is to say, Farley's (2001a) structured-output task is different from the one applied in Morgan-Short and Bowden's (2006) study where the latter engaged learners to process the target grammatical form meaningfully in order that they were be able to complete the tasks successfully.
The notion of task-essentialness might also explain why the subjects in the text reconstruction task and reading comprehension group in Wong's (2015) study failed to make any gains after the treatment. That is, the subjects in both text reconstruction task and reading comprehension group were not required to attend to the target structure to complete the tasks given.

Another main problem in many studies on PI is related to how comprehension and production skills were conceptualized and tested. That is, although it is frequently claimed that PI is effective in developing both comprehension and production skills, the tests used to assess the skills, however, might be problematical. According to Shintani (2015a), the test contents used to assess the interpretation skills were, to a great extent, similar to the materials used in teaching the PI groups. Furthermore, the instruments used in assessing the production skills were also very low in terms of validity. For instance, the production tests used in VanPatten, Farmer and Clardy's (2009) study did not require the subjects to produce any sentences, let alone a text. Instead, the tests only required the subjects to do a gap-filling activity. Meanwhile, in other PI studies, the production tests only included sentence-completion tasks. These two types of measurements (gap-filling and sentence-completion) are, in fact, still prevalent in the studies on PI (e.g., Benati, 2015; Benati \& Angelovska, 2015; White, 2015). Even if the researchers claimed to have applied discourse-based tests in assessing interpretation and production skills in their study, the discourse-based tests they employed, however, were very simple and not far different from a sentence-based test (e.g., Benati, 2015; Wong, 2015; VanPatten \& Uludag, 2011). Hence, the claim that PI is effective in developing production skills might still be premature, for the skills measured through blank-filling, sentence completion and sentence-based tests are not the same as the skills of using the target language, and thus target grammatical structures, in natural communication contexts (cf., Ellis, 2002).

\section{CONCLUSION}

After a decade of Ellis's (2006) review of the prevailing issues in L2 grammar instruction, it appears that there is still no a definitive solution to the main problem he raised in the article, i.e., how grammar should be taught in a way that promotes acquisition (however, see Rasuki, 2017; Shintani, $2015 \mathrm{~b}$ for quite recent developments in teaching grammar drawing on Ellis' (2006 and elsewhere) proposal). With regard specifically to PI, the most pressing question that future studies on PI need to address is: "how exactly are the outcomes of learning through PI transferred to skill development?". This question is related to the claim put forward by VanPatten (2015a) that PI "assists in developing underlying knowledge that can be tapped during the development of skill" (p. 100). Hence, this review calls for more rigorous studies on PI. First, it argues that future studies on PI need to be conducted for a longer duration, for most studies on PI were conducted in a very short period of time (e.g. Wong, 2015; Benati, 2015). Second, better operationalization of the instructional options with which PI is compared is required, 
since a number of instructional options were operationalized inconsistently. Third, further studies also need to include more discourse-level materials and tests rather than sets of sentences (e.g. VanPatten \& Uludag, 2011; Benati, 2015; Wong, 2015). This is of paramount importance to address the pressing question stated above. Fourth, following DeKeyser and Botana (2015), further studies on PI need to include participants from a variety of language backgrounds.

It is necessary to note, however, that although this review puts forward a number of limitations of a number of studies on PI, it is by no means intended to diminish the efficacy of PI. Rather, this review is motivated by the potential that PI holds for effective grammar instruction. That is, although the theoretical rationales underlying this instructional option may appear perplexing for teachers, the pedagogical procedures are highly practical and are probably effective, especially as compared with the conventional/traditional methods aiming to teach grammatical rules explicitly to learners. Considering the practicality and relative effectiveness of this instructional option, it is expected therefore that this review of issues will be able to motivate teachers and/or researchers to further investigate issues related to this instructional option.

\section{ACKNOWLEDGEMENT}

The author would like to acknowledge the tremendous support he has received from Lembaga Pengelola Dana Pendidikan (LPDP), Ministry of Finance, Republic of Indonesia, throughout the whole process of the study. He also would like to thank two anonymous reviewers for their constructive comments on this article.

\section{REFERENCES}

Benati, A. (2005). The effects of Processing Instruction, traditional instruction, and Meaning-Output Instruction on the acquisition of the English past simple tense. Language Teaching Research, 9(1), 67-93. doi: 10.1191/13621688051r154oa

Benati, A. (2015). The effects of re-exposure to instruction and the use of discourse-level interpretation tasks on Processing Instruction and the Japanese passive. International Review of Applied Linguistics in Language Teaching, 53(2), 127-150. doi: 10.1515/iral-2015-0007

Benati, A., \& Angelovska, T. (2015). The effects of Processing Instruction on the acquisition of English simple past tense: Age and cognitive task demands. International Review of Applied Linguistics in Language Teaching, 53(2), 249-269. doi: 10.1515/iral-2015-0012

Cadierno, T. (1995). Formal instruction from a processing perspective: An investigation into the Spanish past tense. Modern Language Journal, 79(2), 179-193. doi: 10.1111/j.1540-4781.1995.tb05430.x

Cox, J. G., \& Sanz, C. (2015). Deconstructing PI for the ages: Explicit instruction vs. practice in young and older adult bilinguals. International Review of Applied Linguistics in Language Teaching, 53(2), 225-248. doi: 10.1515/ iral-2015-0011
Dekeyser, R., \& Botana, G. P. (2015). The effectiveness of Processing Instruction in L2 grammar acquisition: A narrative review. Applied Linguistics, 36(3), 290-305. doi: 10.1093/applin/amu071

DeKeyser, R., Salaberry, R., Robinson, P. \& Harrington, M. (2002). What gets processed in Processing Instruction? A commentary on Bill VanPatten's "Processing instruction: An update". Language Learning, 52(4), 805-823. doi: 10.1111/1467-9922.00204

Ellis, R. (2002). Does form-focused instruction affect the acquisition of implicit knowledge? A review of the research. Studies in second language acquisition, 24(2), 223-236. doi: 10.1017/S0272263102002073

Ellis, R. (2006). Current issues in the teaching of grammar: An SLA perspective. TESOL Quarterly, 40(1), 83-107. doi: $10.2307 / 40264512$

Farley, A. P. (2001a). Authentic Processing Instruction and the Spanish subjunctive. Hispania, 84(2), 289-299. Retrieved from http://www.jstor.org/stable/3657760

Farley, A. P. (2001b). Processing Instruction and Meaning-Based Output Instruction: A comparative study. Studies in Applied Linguistics, 5, 57-93. Retrieved from http://www.jstor.org/stable/40648285

Farley, A. P. (2004). The relative effects of processing instruction and meaning-based output instruction. In B. VanPatten (Ed.), Processing instruction: Theory, reserarch, and commentary (pp. 143-168). Mahwah, NJ: Lawrence Erlbaum and Associates.

Keating, G. D., \& Farley, A. (2008). Processing Instruction, Meaning-Based Output Instruction, and Meaning-Based Drills: Impacts on classroom L2 acquisition of Spanish object pronouns. Hispania, 91(3), 639-50. Retrieved fromhttp://www.jstor.org/stable/40648167

Loschky, L., \& Bley-Vroman, R. (1993). Grammar and taskbased methodology. In G. Crookes \& S. Gass (Eds.), Tasks and Language Learning: Integrating Theory and Practice (pp. 123-167). Philadelphia: Multilingual Matters.

Morgan-Short, K., \& Bowden, H. W. (2006). Processing Instruction and Meaningful Output-Based Instruction: Effects on second language development. Studies in Second Language Acquisition, 28(1), 31-65. doi: 10.1017/ S0272263106060025

Qin, J. (2008). The effect of Processing Instruction and Dictogloss tasks on acquisition of the English passive voice. Language Teaching Research, 12(1), 61-82. doi: 10.1177/1362168807084494

Rasuki, M. (2017). The Incidental Acquisition of English Nominal Structures by a Young EFL Learner under Comprehension-based Lessons. International Journal of Applied Linguistics and English Literature, 6(4), 4551. doi:10.7575/aiac.ijalel.v.6n.4p.45

Shintani, N. (2015). The effectiveness of Processing Instruction and Production-Based Instruction on L2 grammar acquisition: A meta-analysis. Applied Linguistics, 36(3), 306-325. doi: 10.1093/applin/amu067

Shintani, N., (2015b). The incidental grammar acquisition in focus on form and focus on forms instruction for young beginner learners. TESOL Quarterly, 49(1), 115-140. doi: $10.1002 /$ tesq. 166 
VanPatten, B. (1996). Input processing and grammar instruction: Theory and research. Norwood, NJ: Ablex.

VanPatten, B. (2002). Processing instruction: An update. Language Learning, 52(4), 755- 804. doi: 10.1111/14679922.00203

VanPatten, B. (ed.) (2004). Processing instruction: Theory, research, and commentary. Mahwah, NJ: Lawrence Erlbaum.

VanPatten, B. (2015a). Foundations of Processing Instruction. International Review of Applied Linguistics in Language Teaching, 53(2), 91-109.

VanPatten, B. (2015b). Input processing in adult SLA. In B. VanPatten \& J. Williams (Eds). Theories in second language acquisition: An introduction (pp. 113-134). New York, NY: Routledge.

VanPatten, B., \& Cadierno, T. (1993). Explicit instruction and input processing. Studies in second language acquisition, 15(02), 225-243. doi: 10.1017/ S0272263100011979

VanPatten, B., \& Uludag, O. (2011). Transfer of training and processing instruction: From input to output. System, 39(1), 44-53. doi:10.1016/j.system.2011.01.013

VanPatten, B., \& Wong, W. (2004). Processing instruction and the French causative: Another replication. In B. VanPatten (Ed.), Processing Instruction: Theory, research, and commentary (pp. 97-118). Mahwah, NJ: Lawrence Erlbaum.
VanPatten, B., Collopy, E., Price, J. E., Borst, S., \& Qualin, A. (2013). Explicit information, grammatical sensitivity, and the first-noun principle: A cross-linguistic study in processing instruction. The Modern Language Journal, 97(2), 506-527. doi: 10.1111/j.1540-4781.2013.12007.x

VanPatten, B., Farmer, J. L., \& Clardy, C. L. (2009). Processing instruction and meaning-based output instruction: A response to Keating and Farley (2008). Hispania, 116-126. Retrieved from http://www.jstor.org/ stable/40648285

VanPatten, B., Inclezan, D., Salazar, H., \& Farley, A. P. (2009). Processing Instruction and dictogloss: A study on object pronouns and word order in Spanish. Foreign Language Annals, 42(3), 557-575. doi: 10.1111/j.19449720.2009.01033.x

White, J. (2015). Primary and secondary effects of processing instruction on Spanish clitic pronouns. International Review of Applied Linguistics in Language Teaching, 53(2), 151-179. doi: 10.1515/iral-2015-0008

Wong, W. (2004). The nature of Processing Instruction. In B. VanPatten (Ed.), Processing Instruction: Theory, research, and commentary (pp. 33-65). Mahwah, NJ: Lawrence Erlbaum.

Wong, W. (2015). Input, input processing, and output: A study with discourse-level input and the French causative. International Review of Applied Linguistics in Language Teaching, 53(2), 181-202. doi: 10.1515/iral-2015-0009 